\title{
OS MISERÁVEIS E A CAUSA DO POVO ${ }^{1}$
}

Walnice Nogueira Galvão

Universidade de São Paulo (USP)

\section{RESUMO}

Grande poeta e dramaturgo, Victor Hugo destacou-se igualmente no romance: Os miseráveis constitui um marco no desenvolvimento do gênero épico. Inextricavelmente ligado à militância do autor em prol dos oprimidos, assinala o ponto mais alto da vocação humanitária do Romantismo, seu senso messiânico e seu sopro titânico. Na literatura brasileira a grife do Mestre assinalaria a obra de vários discípulos, entre outros Castro Alves e Euclides da Cunha.

\section{ABSTRACT}

A great poet and playwriter, Victor Hugo also wrote novels: Les misérables is a benchmark in the epic genre's evolution. Paralel to the author's activism in defense of the poor and opressed, it highlights Romanticism's humanitarian vocation, as well as its messianism and titanic breath. In Brazilian literature, the Master left its imprinting in many disciples, among them Castro Alves and Euclides da Cunha.

\section{PALAVRAS-CHAVE:}

Romance;

Romantismo;

Digressão;

Revolução Francesa;

Povo.

\section{KEYWORDS:}

Novel;

Romanticism;

Digression;

French Revolution;

People.

\footnotetext{
${ }^{1}$ A revista Literatura e Sociedade agradece à Fundação Perseu Abramo a autorização para reproduzir este ensaio sobre Os miseráveis, que faz parte de um volume mais amplo intitulado: Walnice Nogueira Galvão, Victor Hugo - A águia e o leão (Escritos políticos e crítica social). São Paulo: Fundação Perseu Abramo, 2018 (a sair).
} 
"Sombre fidélité pour les choses tombées, Soit ma force et ma joie et mon pilier d'airain!".

Victor Hugo

1 popularidade de Victor Hugo sobrevive graças a Os miseráveis (1862), a única de suas obras que parece mostrar perene vitalidade. Quase tudo o mais está praticamente esquecido, mas Os miseráveis continua recebendo as atenções, quando não as paixões. ${ }^{2}$

É, de longe, a mais popular e popularizada, a mais reeditada e adaptada até hoje, e em diferentes veículos: cinema, teatro, histórias em quadrinhos, musicais recentes. Em pleno fastígio da grande ficção realista de Balzac (então já falecido) e Flaubert, às vésperas de Zola, surge este heterodoxo, tardio representante do romance romântico. A começar por sua extensão torrencial: na atual edição brasileira, dois volumes num total de 2 mil páginas ou 500 mil palavras. Figurando entre os mais reeditados romances da literatura ocidental, atingiu leitores aos milhões, desde que a primeira edição logo se esgotou. Ao tempo do filme mudo já ganhava versões nas telas. E, além de peça de teatro, também se transformou em musical, com imenso sucesso. Por tudo isso, e por ser veículo privilegiado para as ideias políticas de Victor Hugo, pede uma pausa atenta.

Ao lado do grande romance realista, o apogeu do romance-folhetim fora atingido pouco antes com Os mistérios de Paris, de Eugène Sue, até hoje o mais famoso exemplo, publicado em capítulos diários de jornal entre 1842 e 1843. Desde sua época, atribuem-lhe poderes de arregimentação para a Revolução de 1848 - descontando-se o seu tanto de exagero. A calorosa reação do público de todas as classes, o fervor com que seguia as aventuras descabeladas, o mergulho na miséria que exigiu de seu autor: o fato é que Sue, de saída um dândi, foi sendo transformado por seu livro à medida que o escrevia. Quando terminou, era um socialista e um revolucionário, e o dândi arrependido foi eleito deputado em 1848.

O entrecho passa-se todo em Paris, e muito em seu bas-fond, ou seja, no submundo de lúmpens e marginais. Marx e Engels não o apreciaram, desancando-o em A sagrada família, chamando-o de sentimental e alienante.

\footnotetext{
2 David Bellos, The novel of the century: The extraordinary adventure of 'Les misérables'. Inglaterra: Particular Books/Penguin, 2017.
} 
Mas a fórmula ali está: intriga mirabolante, cheia de suspense para obrigar à compra do jornal no dia seguinte, identidades secretas ou trocadas, falsas confidências, crianças roubadas na infância, vendetas intermináveis, irmãos inimigos, amores proibidos, papeis secretos, castidade em perigo, bons premiados e maus castigados. Assim também procede Os miseráveis, acusando a sombra do modelo do romance-folhetim, em voga nesses anos.

Pode-se dizer que Os miseráveis é um romance folhetinesco, apesar de não ter sido publicado em folhetins. Constitui um painel da História e da sociedade francesa de sua época, focalizando o período de convulsões da Monarquia de Julho, instalada em 1830, detendo-se mais precisamente no levante de 1832. Mas foi publicado bem depois, em 1862, sendo, portanto, contemporâneo de Um conto de duas cidades (A tale of two cities), de Charles Dickens, uma raridade entre os romances por ter como assunto a Revolução Francesa. E duplamente raridade, porque o autor, afora ser estrangeiro, não praticava o romance histórico. Sua leitura abre oportunidade para reflexões sobre a representação do povo sublevado.

Como seria de esperar numa narrativa romântica, Os miseráveis oferece um entrecho complicadíssimo, cheio de reviravoltas e revelações. Sem falar na desproporção entre as partes, já que é sujeito a vastas digressões.

Aquilo que Victor Hugo propõe no prefácio de sua peça de teatro Cromwell como estética para o drama burguês, vai pôr em prática igualmente nos romances: mistura de gêneros (tragédia com comédia); multiplicação dos espaços e dos tempos (abaixo a unidade de tempo e de lugar da convenção neoclássica para teatro); multiplicação da ação (abaixo a unidade de ação); multiplicação de personagens de diferentes estágios da sociedade (pobres, ricos, nobres, camponeses, operários, religiosos, etc.); mistura de grotesco com sublime; incorporação de aspectos menos nobres da vida. As personagens, então, são em geral ou boas ou más, não havendo muita transição nem nuances entre elas.

Ao deflagrar a ação a partir de um episódio decisivo - o roubo de um pão para matar a fome -, o romance propõe-se a demonstrar a injustiça de um sistema inteiro que, a partir de um delito insignificante, vai-se encarniçar contra um pobre-diabo até mantê-lo no cárcere por 29 anos. Ele é, a essa altura e com essa escola, um bruto, mas uma série de acasos e de pessoas que o destino põe em seu caminho vão elevá-lo e conduzi-lo à redenção, através do amor e da caridade.

Jean Valjean é o protagonista e o Inspetor Javert o implacável perseguidor, acreditando tanto na lei, que faz do desmascaramento de sua presa um objetivo de vida. Mas entre uma coisa e outra inúmeros incidentes ocorrem e inúmeras personagens intervêm.

Entre os bons figura em primeiro lugar o Bispo Myriel, que dá a Jean Valjean, que saiu da prisão e passa fome, uma chance, mentindo à polícia 
para protegê-lo, mesmo tendo sido por ele roubado. Esse ato de caridade vai transformar todo o futuro de Jean Valjean. Mais tarde vamos encontrálo prefeito de uma pequena cidade, cidadão virtuoso e atento aos pobres, empresário modesto que dá trabalho aos necessitados.

Entre os maus sobressaem Thénadier e sua família, simbolizando o pobre corrupto, ou que foi corrompido pela pobreza, que sobrevive explorando e exercendo seu sadismo sobre pobres desamparados, como Cosette, que mais tarde se tornará filha adotiva de Jean Valjean. Cosette vai formar com Marius, bondoso e sério, o casal romântico.

Este, em grossos traços, é o entrecho de Os miseráveis. Mas talvez o entrecho não seja o mais importante, e sim o sopro humanitário que percorre todo o romance.

\section{O povo no romance - antecedentes}

A grande novidade que Victor Hugo traz para o romance é a personagem coletiva povo.

Como se sabe, o povo não era assunto literário. O gênero épico se manifestava na epopeia aristocrática, a exemplo daquelas da Antiguidade, cujas personagens eram reis de cidades-estado, ou as da Idade Média, com seus príncipes, condes e barões.

Paralelamente, havia uma literatura popular sobretudo cômica e paródica, estudada por Bakhtin, com sagas cheias de humor frequentemente grosseiro, como a do Aventureiro Simplicissimus na Alemanha; ou a obra de Rabelais com Gargantua e Pantagruel, na França; ou a novela picaresca, na Espanha. Enquanto a epopeia ou a épica de herói se expressava em estilo elevado, a literatura popular era em estilo baixo, com incorporação do deboche e do baixo corporal. Nesse sentido, pode-se dizer que aquele que é considerado o primeiro romance, o D. Quixote, de Cervantes, abebera-se nas duas vertentes.

Mas houve a Revolução Francesa, e tudo mudou. Pela primeira vez na História uma classe foi apeada do poder. Até então, acreditava-se que isso era impossível, que havia razões inclusive da ordem do sagrado - o direito divino dos reis - para que a aristocracia fosse o estamento dominante e a monarquia a forma de governo decretada por Deus. A Revolução Francesa demonstrou o erro dessa concepção e não só derrubou a aristocracia como aboliu a monarquia e decapitou o rei. Do âmbito dos Estados Gerais, e mais exatamente do Terceiro Estado - uma combinação de várias camadas sociais, exceto nobreza e clero - sairia a nova classe dominante, a burguesia.

Só a partir de então o povo foi aparecendo como personagem literário. 
O primeiro a chamar a atenção para tal fenômeno foi o historiador francês Michelet, um contemporâneo de Victor Hugo que escreveu livros interessantíssimos, em que reivindicava para o povo o papel de "agente da História". Até então, os historiadores e as crônicas de governo davam o papel principal aos líderes, aos monarcas, aos príncipes, aos generais. Michelet afirma que nada disso correspondia à verdade e que quem fazia a História era o povo. Republicano ferrenho, defendia os ideais igualitários e de livre-pensamento da Revolução Francesa. Foi, por isso, quando da Restauração monárquica, destituído de sua cátedra no Collège de France, que nunca recuperou. É autor de monumentais tratados como uma História Universal em vinte volumes, uma História da Revolução Francesa etc. que são vastas realizações, mas também de livros de um volume só sobre assuntos que abriram caminho, como As mulheres ou A feiticeira.

Ora, Victor Hugo consagrou-se a fazer do povo o protagonista de sua ficção. Os miseráveis, mas também Nossa Senhora de Paris, Os trabalhadores do mar e $O$ noventa e três, devotam-se a esse projeto. É bom lembrar que Charles Dickens vai exercer esse papel na Inglaterra, escrevendo numerosos romances em que, em vez da vida nas cortes e nos castelos, o dia-a-dia dos pobres é representado. Grandes esperanças, Oliver Twist, David Copperfield, e muitos outros, trazem à cena os horrores infligidos aos pobres pelas transformações violentas da Revolução Industrial.

Depois de Victor Hugo, já em pleno Naturalismo, Emile Zola assumirá o revezamento. Germinal é a crônica de uma greve de mineiros; L'Assomoir ou A taverna é a história de um operário que mergulha na miséria e na bebida; e assim por diante. No Brasil, demorou um pouco. Houve tentativas de vários autores românticos e naturalistas, que se empenharam em delinear literariamente os diferentes "tipos humanos" espalhados pela vastidão do país. E os pobres só vão receber as honras de entrar na literatura como protagonistas pelas mãos de Aluísio de Azevedo em $O$ cortiço e de Euclides da Cunha, em Os sertões, já na virada de século.

\section{De como o povo perturba o romance: o "projeto burguês"}

O percurso interno do romance-padrão novecentista pode ser assim resumido: os anos de aprendizagem de uma criança do sexo masculino que passa da adolescência à idade adulta através da descoberta do mundo, aí incluindo a educação de emoções e sentimentos, chegando a uma maturidade que implica em desilusão e aceitação. Ou seja, o mundo e os homens, bem como sua capacidade de ser um deles, aparecem ao final como diminuídos.

Divisa-se por trás disso tudo o projeto burguês. Ou seja, a questão se coloca não só no plano psicológico e existencial como parece ser o 
consenso, mas se trata, muito concretamente, de ascensão social, de "subir na vida", e é disso que o romance novecentista fala.

Em certos autores o projeto burguês fica ainda mais claro. Em Balzac por exemplo, muito lúcido a respeito. Algumas de suas personagens são até hoje tomadas como paradigma dessa ascensão social a qualquer preço, em geral à custa da venalidade das consciências, que vão fazendo concessões uma atrás da outra. Mas igualmente à custa das mulheres: primeiro à custa da mãe e das irmãs, que ficam na província, mergulhadas na pobreza, gastando as mãos e as esperanças depositadas no herdeiro masculino. Costuram suas roupas, o pouco que têm ou que ganham com trabalhos manuais vai para sustentá-lo em Paris - que é onde estão as oportunidades. Em seguida, esses heróis entram para a corte de uma grande dama, e vão trocando de salão sempre por outro mais luzido. Tornam-se amantes de uma dama muito rica - e chegaram aonde queriam, agora têm uma plataforma para construir a carreira.

O melhor exemplo até hoje é Rastignac, que desponta em Paris, vindo da província, aos 21 anos, cheio de energia e ambição. Aparece em vários romances, a começar pelo Pai Goriot e depois secundariamente em outros. Rapidamente, enquanto sócio do marido de sua amante, a baronesa de Nucingen, torna-se banqueiro, conde e par-de-França, bem como ministro por duas vezes, até se casar com a filha de sua amante. Dizem que Balzac se inspirou na figura de Thiers, que fez um percurso semelhante até tornar-se presidente da República. Há vários outros em sua obra, inclusive em As ilusões perdidas, cujo protagonista, Lucien de Rubempré, percorre caminho semelhante. Mas Balzac é especial, porque se dedicou a estudar a circulação do dinheiro, isto é, por que meios e a que preço, para os bons sentimentos e a honestidade, o dinheiro passava de mãos em mãos. É nele que encontramos o estudo mais frio do projeto burguês, enquanto os demais escritores às vezes se deixam engambelar pela cortina de fumaça da ética ou dos laços familiares e sentimentais.

Tomemos Stendhal, por exemplo. É de sua autoria um dos mais bem realizados romances que se conhecem, O vermelho e o negro: Julien Sorel é outro até hoje tomado como exemplo. A perfeição desse romance, esteticamente falando, ajuda a entender melhor o que se passa na literatura. Desde a primeira cena, em que o vemos como um pequeno camponês pobre ajudando o pai, até sua ascensão como amante de damas da aristocracia, primeiro da província e depois de Paris, vamos acompanhando suas peripécias, admirando sua audácia e seu empenho fulgurante em conquistar o mundo. Até que termina na guilhotina devido a um crime cometido sob grande emoção - e que atrapalha seu projeto. Não subjugou suas emoções, refreando-as e dirigindo-as para um alvo único.

Julien Sorel era fruto da Revolução Francesa, assim como seu autor, que foi soldado nas guerras napoleônicas e depois disso andou exilado por 
longo tempo. E é preciso lembrar que foi a Revolução que tornou tudo possível, solapando a hierarquia rígida da sociedade, segundo a qual alguém nascia e morria na mesma posição de classe. Depois dela, tudo era possível, podia-se nascer plebeu e morrer imperador, como foi o caso de Napoleão, obscuro militar de baixa patente ("le petit caporal") de obscura origem na pequena nobreza de uma obscura e remota província, a Córsega, que nem bem francesa era. E são célebres nas guerras da Revolução os "generais de 20 anos", que chegavam à patente graças exclusivamente a seus méritos: o próprio Napoleão tornou-se general aos 24 anos.

Os miseráveis é mais simpático, em seu escopo e em seu âmbito bem mais amplo que o usual, mas no fundo também é um enredo de projeto burguês. Jean Valjean é o miserável que origina todo o romance, ao furtar um pão para matar a fome, por isso acabando nos trabalhos forçados por três décadas. A desproporção entre o delito e a punição fala por si. Narrativa cheia de altos e baixos, de reviravoltas surpreendentes, diverge do movimento comum do romance da época que é só ascensional, tendo em vista a realização do projeto burguês. Mas vai terminar de novo no alto.

\section{Desvios de rota}

O leitor vai-se deparar com muitas digressões, históricas umas, literárias outras. Cada uma das duas metades do romance é marcada por uma delas: a batalha de Waterloo na primeira metade (a morte da Revolução) e a Barricada de Paris na segunda metade (a ressurreição da Revolução).

As mesmas guerras napoleônicas deram ensejo a três notáveis batalhas literárias ${ }^{3}$.

Em Os miseráveis é Waterloo, a batalha em que a fase decisiva da Revolução Francesa chegou ao fim e Napoleão foi derrotado pela coalizão das forças monarquistas e reacionárias, em 1815. Foi o fim também da Grande Armée, o primeiro exército popular da História ${ }^{4}$. A importância histórica de Waterloo não se discute. Em compensação, a relação das personagens do romance com Waterloo é um fio tênue apenas, nem merece propriamente um episódio. No fim da digressão, o vilão Thénadier, que percorre o campo de batalha para pilhar pertences dos mortos e feridos, resgata o corpo inerte do pai de Marius (o herói romântico) que jaz sob um monte de cadáveres para despojá-lo, com isso salvando sua vida e ganhando sua gratidão, tão eterna quanto imerecida.

\footnotetext{
${ }^{3}$ Antonio Candido, "Batalhas", O albatroz e o chinês. Rio de Janeiro: Ouro sobre Azul, 2010, 2a . ed. aum., 2010.

${ }^{4}$ Se considerarmos, talvez com excesso de rigor, que as hostes de Espártaco não eram propriamente um exército.
} 
Em A cartuxa de Parma, de Stendhal, trata-se da mesma Waterloo, de que Fabrício del Dongo, o protagonista, participa. Todavia, falta-lhe uma noção geral das forças em presença, já que fora levado até ali graças a seu entusiasmo por Napoleão. Fica claro que a ocupação napoleônica levara a modernidade às cidades da península italiana, que, sob dominação austríaca, viviam mergulhadas no pior atraso social: sua mãe e sua tia também eram fãs do imperador. Fabrício apenas vislumbra alguns dos lances, embora se empenhe na luta.

Em Guerra e paz, de Tolstói, temos mais a batalha de Austerlitz, e um pouco menos a de Borodino. Na de Austerlitz, o conflito é visto pela perspectiva do príncipe André Bolkonski, ajudante de campo do comandante-em-chefe das forças russas, o general Kutusov. Na de Borodino, Pedro Besukov é apenas um observador não-beligerante; mas, ao acabar ajudando a carregar os canhões, é capturado pelos franceses, de modo que termina participando da Grande Retirada e seus horrores.

Em suma, a mesma experiência das guerras napoleônicas é crucial para a geração pós-revolucionária de escritores, que não viveu a Revolução Francesa mas chegou à maioridade em seguida ${ }^{5}$. Os três autores escrevem em meados do séc. XIX: já passou a Revolução, já passou Waterloo, já se instalou a Restauração. Mas a Revolução ainda é o evento determinante do enredo. Claramente, é também determinante na formação de suas personagens.

Teria Waterloo tanto valor para Os miseráveis quanto a Revolução de 1848, de que Victor Hugo participou dilacerado por contradições e devido à qual entrou num processo vital sem volta que o arrastaria ao exílio por vinte anos? Algumas datas podem esclarecer a questão e fincar algumas balizas.

A Monarquia de Julho e os motins populares de 1830 a 1832 fornecem explicitamente o enredo de Os miseráveis. Mas Victor Hugo participou de 1848, revolução sobre a qual escreveu muitas coisas, e também de 1851, quando do golpe de estado de Luís Bonaparte. E é bem depois disso que surge Os miseráveis, que sairia em 1862: já imbuído, portanto, dessa tremenda experiência, quando o escritor testemunhou pessoalmente o potencial criador das energias plebeias mas também viu as forças da ordem massacrando o povo nas ruas. E a barricada que elege como paradigma é uma das muitas de 1848, com sua data registrada no texto.

Falará, entretanto, de outras, compatíveis com o período do enredo, que é a Monarquia de Julho. Afora 1848, participou da resistência popular de três dias ao golpe de estado de Luís Bonaparte (culminando no massacre

\footnotetext{
${ }^{5}$ George Steiner, “The great ennui”, In: Bluebeard's castle. Londres: Faber \& Faber, 1971.
} 
nas ruas de Paris no dia 4 de dezembro de 1851), pelo qual este se tornou ditador e mais tarde imperador. Espicaçado por este último trauma, logo escreveria Napoleão o Pequeno (Napoléon le Petit), em 1852, e bem mais tarde História de um crime (Histoire d'un crime), em 1877, em que opera o exame minucioso das dezenas de barricadas erigidas pelo povo, conforme sua contagem nas ruas de Paris.

No início do exílio e contemporâneo a Napoleão o Pequeno, escreveria sobre os mesmos eventos um dos mais notáveis livros de poesia política de toda a história da literatura, Os castigos (Les châtiments), de 1853, em que faz o balanço da Revolução Francesa e de tudo o que se seguiu, até o golpe.

Experiências como essas mudaram para sempre o rumo da vida do escritor. Quando regressa do exílio e participa em 1871 da Comuna de Paris, que lhe inspirou um livro de poemas, O ano terrível (L'année terrible), já é um tarimbado militante. Nisso seguiu o exemplo de numerosos intelectuais, escritores e artistas que aderiram à causa do povo, participando da Comuna, ombro a ombro com os communards.

A batalha de Waterloo constitui a maior digressão de Os miseráveis, e, embora crucial para a História, é pouco justificada para a continuidade do enredo. Mas há outras digressões, por exemplo sobre um convento e uma ordem religiosa de freiras, historicamente bem informada e com reflexões sobre o que é ser freira; ou então outra, de trinta páginas, sobre argot, ou gíria, assunto importante em Nossa Senhora de Paris (Notre-Dame de Paris), de 1831, e um capítulo de Os miseráveis; ou ainda sobre o sistema de esgotos da cidade, trecho mais conhecido. Mesmo quando tratam de freiras ou de gíria ou de esgotos, são sempre interessantes, sempre pertinentes, contribuindo para desenhar o mural histórico que está sendo montado.

Se aquilatarmos como essas digressões interferem no entrecho, concluiremos que Victor Hugo não resiste, dado seu perfil, a fornecer o quadro histórico a cada passo. Mas justamente esse afã de historiador faz o leitor compreender melhor a trajetória do protagonista - porque o que se passa com ele não é apenas da ordem da ficção mas está profundamente imbricado na História com $\mathrm{H}$ maiúsculo, e na história da França em particular.

\section{As barricadas}

Passemos à segunda grande digressão, a das barricadas em Paris.

Em 1830, a insurreição derruba Carlos X e sobe ao trono Luís Filipe I. Este era filho de um revolucionário de 1789, representante eleito da nobreza nos Estados Gerais, jacobino que votara pela morte do rei e acabara guilhotinado no Terror. Por isso fora alcunhado "Filipe Égalité". 
Mas o novo rei cairá também, em 1848, quando a revolução se alastra pela Europa inteira, que queria seguir o exemplo da França, extinguindo o Antigo Regime e tornando-se republicana.

Todo o romance converge e culmina nesta que é a maior digressão da segunda metade. Embora comece pela descrição da barricada de 1848, vai narrar a insurreição de 1832, deflagrada pelas exéquias solenes e cerimoniais do general Lamarque. Este, querido pelo povo, fora general de Napoleão e se destacara na defesa da Revolução e da França. O féretro, à medida que atravessa as ruas de Paris, vai acendendo as fagulhas de um descontentamento generalizado, até instalar-se o levante - que não durará mais que os dias 5 e 6 de junho. No fim dela, Jean Valjean interfere e salva a vida de Marius, subtraindo-o à repressão. O moleque Gavroche, personagem crucial, tomba morto, atingido por uma bala. Os líderes são executados por fuzilamento, ali mesmo ao pé da barricada, pela Guarda Nacional.

Após essa digressão, o romance, que a essa altura já se aproxima do fim, volta à corrente principal do entrecho, ou seja, à história de Jean Valjean.

Quanto aos inúmeros meandros da intriga, a ponto de desnortear o leitor, que ignora o que está acontecendo com o herói Jean Valjean ou com seu perseguidor o Inspetor Javert, é preciso lembrar que o escopo do livro é traçar um retrato compassivo das lutas populares de seu tempo.

Apesar de tantos extravios do fio da narrativa típicos da forma romance quando ainda tateante - embora a essa altura já tivesse atingido a perfeição com o realismo de Stendhal, Balzac e Flaubert -, Victor Hugo nunca perde de vista que o mais importante é a concepção do povo como "agente da História".

Em suma, o romance começa pela batalha de Waterloo, que assinala, com a queda de Napoleão, o fim do processo que se iniciou em 14 de julho de 1789 com a Tomada da Bastilha. No arco que vai até as barricadas de 1832, no enorme capítulo que narra como a cidade de Paris se ergue numa sublevação, temos a ressurreição da Revolução Francesa, que, apesar de esfrangalhada pelas traições que os poderosos infligiram ao povo, teima em renascer. - Vale lembrar que, depois da Comuna de Paris em 1871, nunca mais houve reis e monarquia na França.

Várias pequenas alusões nesse longo capítulo nos lembram essa ressurreição. Todos querem lutar, até mulheres e crianças. A extraordinária personagem que é o moleque Gavroche mantém-se em pé de guerra, embora seja pequeno demais para carregar um fuzil e tenha que contentarse com a pistola. Sua trajetória ocupa uma parte do enredo.

Em tempo: é dessa época (1833) o célebre quadro do pintor francês Delacroix, "A liberdade guiando o povo", hoje no Louvre. No centro da tela a óleo de vastas dimensões, uma mulher portando o barrete frígio - 
alegoria da Revolução - galga a barricada juncada de mortos, empunhando numa das mãos um fuzil com baioneta calada e na outra a bandeira tricolor. Essa é a bandeira criada pela Revolução, extirpadas as insígnias da realeza, e que se tornaria a bandeira nacional. Ao lado dela, um menino avança, uma pistola em cada mão. Nada nos impede de pensar que seja um "retrato de Gavroche", que Victor Hugo homenagearia em seu romance.

Outras alusões surgem quando os insurretos cantam as canções da Revolução, como Ça Ira e La carmagnole - aquelas que ameaçavam os aristocratas com o cadafalso - e a Marselhesa, apelo aos cidadãos para pegarem em armas contra os inimigos do povo, que se tornaria o hino nacional da França. E quando a bandeira vermelha dos revolucionários vem abaixo sob a fuzilaria inimiga, convoca-se alguém que queira enfrentar a morte certa subindo ao alto da barricada para alçar a bandeira de novo. Quem se apresenta é um velhinho, único por ali que participara da Revolução Francesa, tantos anos antes. Ele cumpre seu dever e tomba morto, baleado. Comenta um circunstante: "Que homens, esses regicidas!".

Desse modo, o livro vai superando as críticas que se poderiam fazer ao romance novecentista pelo individualismo excessivo e pelo atrelamento ao projeto burguês. Aqui, o protagonista e o projeto burguês são postos pelo autor a serviço das lutas populares.

Entretanto, as barricadas parisienses, tão importantes na vida dos cidadãos e na obra de Victor Hugo, estavam com os dias contados 6 . Não escapara às autoridades que seu inesgotável nascedouro era o caldeirão dos bairros centrais de Paris onde se acotovelavam os sans-culottes, reduto de trabalhadores e marginais, refugo do corpo social. Ali nasciam as revoluções: becos e vielas, casas amontoadas, ruas em torcicolo apinhadas de gente, reino da insalubridade e das epidemias, miséria extrema, cadinho de motins. Medidas radicais se faziam urgentes, para dispersar e neutralizar essa população em perpétua sedição latente. Luís Bonaparte não teve dúvidas: chamou Haussmann para chefiar a prefeitura do Sena e deu-lhe carta branca.

Em pouco tempo o centro de Paris estava demolido e sua população expulsa para a periferia, em padrão que outras cidades imitaram a partir de então, inclusive o Rio de Janeiro do prefeito Pereira Passos. Rasgaramse amplas avenidas (os boulevards) que se irradiavam a partir de focos como os raios de uma roda. Todas as moradias vieram abaixo e foram substituídas por prédios homogêneos de seis andares.

Dois objetivos estratégicos comandaram a violência dessa intervenção. Primeiro, criar avenidas e ruas de amplitude exagerada, para

\footnotetext{
${ }^{6}$ Nas jornadas estudantis e operárias de 1968 foram novamente erguidas barricadas no Quartier Latin, quando os amotinados descalçaram o leito das ruas para utilizar os pavés tanto para empilhar quanto para atacar a polícia.
} 
impedir o erguimento de barricadas: becos e vielas, nunca mais. Segundo, desimpedir perspectivas de linha reta entre os bairros populares e os quartéis, para que as forças da repressão chegassem rapidamente.

É essa Paris imperial e monumental que vemos hoje e que foi criada nessa época, com esse intuito. A metamorfose foi longamente estudada por Walter Benjamin, no que ele chamou de "Paris, capital do século XIX", no trabalho das Passagens ${ }^{7}$.

Walnice Nogueira Galvão é professora emérita de Teoria Literária e Literatura Comparada da FFLCH-USP. Foi Professora Visitante nas Universidades de Austin, Iowa City, Columbia, Paris VIII, Freie Universität Berlin, Poitiers, Colônia, École Normale Supérieure, Oxford, Berlin 2. Tem 45 livros publicados, sobre Guimarães Rosa, Euclides da Cunha, crítica da literatura e da cultura. Escreve assiduamente em jornais e revistas.

7 Walter Benjamin, Passagens. Belo Horizonte/São Paulo: UFMG/Imprensa Oficial, 2006. 